\title{
Analysis of Biomass in the Indian State of Gujarat for Sustainable Pellet Production
}

\author{
Debajyoti Bose*and Aditya Mekala \\ College of Engineering Studies, University of Petroleum and Energy Studies, P.O. Bidholi via- Prem Nagar, Dehradun 248007, India
}

\begin{abstract}
Energy from biomass has emerged as a promising source of decentralized energy production from developing countries. This paper highlights the importance of solid biofuel or pellets in the context of green energy. These can be used in co-firing with coal and other heating applications. Assessment is done for certain raw materials which do not create food and fodder conflict in the Indian state of Gujarat. Raw material includes agricultural residues available from that region. Pellets manufactured have low sulfur and chlorine content.
\end{abstract}

Keywords: Biomass; Pellet; Pelletization; Wood chips

\section{Introduction}

Renewable energy primarily refers to solar and wind energy, energy from biomass promises to be a cleaner alternative particularly for developing countries. Green power has very low emissions, carbon neutral and has very low sulfur and chlorine content. Raw biomass material is grinded and undergoes pillarization process where they are compressed to form pellets. These pellets have high mass and energy density compared to the original raw material. The 1990s saw an explosion of energy policy changes around the globe. Driven by economic, environmental, security, and social concerns, energy regulation has been in great flux. Many of the changes are having a profound influence on renewable energy, both from policies explicitly designed to promote renewable energy and from other policies that indirectly influence incentives and barriers for renewable energy [1].

Biomass pellets are proven, cost effective materials which can does not require highly skilled operators as production process is simple and easily understood. Since the operation is eco-friendly, utilities will be eager to develop, acquire and maintain such frameworks. Markets tend to function best when low cost access to good information and skills is available; a pattern pellets confronts to. One third contributor of energy to India is biomass with a potential of 22,536MW - [2] which comprises of solid biomass, which is an organic, non-fossil material of biological origins. Biogas which is principally methane and carbon dioxide is produced by anaerobic digestion of biomass and combusted to produce heat. Currently, India has 3697MW [3] installed capacity. Following is a list of some States with most potential for biomass reduction: Andhra Pradesh (200 MW), Bihar (200 MW), Gujarat (200 MW), Karnataka (300 MW), Maharashtra (1,000 MW), Punjab (150 MW), Tamil Nadu (350 MW), Uttar Pradesh (1,000 MW) [4]. The environmental impacts of fossil fuels often result in real costs to society, in terms of human health (i.e., loss of work days, health care costs), infrastructure decay (i.e., from acid rain), declines in forests and fisheries, and perhaps ultimately, the costs associated with climate change. Dollar costs of environmental externalities are difficult to evaluate and depend on assumptions that can be subject to wide interpretations and discretion [1] (Table 1).

The above mentioned biomass material does not cause food vs. fodder arguments, hence have a pivotal role to play in the fields

\section{\begin{tabular}{|l|l|l|l|l|l}
\hline Prosopis & Sawdust & Cotton Stalk & Wood chips Wood strips Wood waste
\end{tabular}}

Table 1: Present work has studied the following materials for quality combination to produce pellets. of bioenergy. These are mostly agricultural residues and energy crops which do not grow food consumed by humans. Importance of pelletization has to be stresses as it reduces tremendously the chlorine, nitrogen and sulfur content of the biomass, hence making them suitable for co-firing with coal to produce electrical power and other heating applications.

\section{Method}

Analysis were done in terms of proximate and nitrogen, chlorine and sulfur estimations.

\section{Moisture Determination}

$10 \mathrm{gm}$ of powdered sample is carefully weighed.

Let Weight of Sample $=\mathrm{x}_{1}$ Sample is taken on petri dish and kept in oven at $105^{\circ} \mathrm{C}$ for three hours. After three hours sample is taken out, cooled in desiccator and carefully weighed. Weight of sample after heat $=\mathrm{x}_{2}$

$$
\% \text { Moisture }=\frac{X_{1}-X_{2}}{X_{1}} \times 100
$$

\section{Ash Determination}

One gram of sample (grinded) is taken in a silica crucible. The crucible is then kept in a muffle furnace at $250^{\circ} \mathrm{C}$ for one hour followed by $550^{\circ} \mathrm{C}$ for two hours. Hot crucible with sample is taken put and cooled in desiccator. Weight of ash is taken into account.

$$
\text { Ash } \%=\frac{\text { Weight of the ash }}{\text { SampleWeight }} \times 100
$$

\section{Volatile Matter Content Determination}

Weight of silica crucible and lid is taken $\left(\mathrm{X}_{1}\right)$. One gram sample

*Corresponding author: Debajyoti Bose, College of Engineering Studies, University of Petroleum and Energy Studies, P.O. Bidholi via- Prem Nagar Dehradun 248007, India, Tel:+919831780513; E-mail: debajyoti1024@gmail.com

Received: September 17, 2015; Accepted: September 26, 2015; Published: October 03, 2015

Citation: Bose D, Mekala A (2015) Analysis of Biomass in the Indian State of Gujarat for Sustainable Pellet Production. J Bioengineer \& Biomedical Sci 5: 166. doi:10.4172/2155- 9538.1000166

Copyright: ( 2015 Bose D, et al. This is an open-access article distributed under the terms of the Creative Commons Attribution License, which permits unrestricted use, distribution, and reproduction in any medium, provided the original author and source are credited. 
is added to the crucible and lid system and weighed $\left(\mathrm{X}_{2}\right)$. Setup is subjected to heat at $900^{\circ} \mathrm{C}$ for seven minutes in a muffle furnace. Cooled in desiccator, setup is again weighed $\left(\mathrm{X}_{3}\right)$; precautions are taken to make sure the lid does not open.

$$
\text { Volatile Matter } \left.\%=\left\{\frac{\left(X_{1}-X_{3}\right)}{X_{2}-X_{1}} \times 100\right)-\mathrm{M}\right\} \times\{100 \div(100-\mathrm{M})\}
$$

\section{Fixed Carbon Determination}

Fixed Carbon $\%=100-\{\%$ Volatile matter $+\%$ ash $+\%$ moisture $\}$

\section{Bulk Density Calculation}

Empty container is taken and weighed $\left(\mathrm{X}_{1}\right)$. Container is now filled with the sample whose BD is to be measured. Surplus material is removed. Container is weighed $\left(\mathrm{X}_{2}\right)$. Result is repeated and an average value is taken.

$$
B D=\frac{\text { Weight of the filled conainer }- \text { Weight of the empty conatiner }}{\text { Volume of the conatiner }}
$$

$\mathrm{BD}=$ Bulk Density in $\mathrm{Kg} / \mathrm{m}^{3}$

\section{Gross Calorific Value Determination}

Two important component of the setup are the oxygen cylinder and the bomb calorimeter. A $5 \mathrm{~cm}$ Nichrome wire is measured and taken and inserted into slots in electrodes and compressed by adjustable caps. Ignition requires $10 \mathrm{~cm}$ thread to carry flame and accordingly it is setup. To the bomb 1-2 $\mathrm{ml}$ distill water is added. The oxygen assembly is connected to the bomb, connections are made tight. Pressure gauge is observed as oxygen flows into the system, taken up to $20 \mathrm{~kg} / \mathrm{cm}^{3}$ and then valve is closed. Bomb is placed in calorimeter and distill water is added until it is fully immersed. Water temperature is setup at $24.5^{\circ} \mathrm{C}$. Bomb has the pellet sample (weighing less than $1.10 \mathrm{gm}$ ) which is connected to the nichrome wire through the cotton thread, in a pure oxygen environment for ignition. After adjusting the zero, the bomb is triggered, rise in temperature is noted. Value reaches peak point and then starts dropping. The peak value is recorded.

$$
G C V=\frac{T \times W-\left(C V_{T}-C V_{W}\right)}{M}
$$

GCV: Gross Calorific Value in $\mathrm{Kcal} / \mathrm{Kg}$

T: Final Temp. Rise in deg. Celsius

$$
\text { W: Water Constant (2561.85) }
$$

M: Mass of biomass sample

$\mathrm{CV}_{\mathrm{T}}$ : Calorific Value of cotton thread $(1 \mathrm{~cm}=2.1 \mathrm{Kcal} / \mathrm{Kg})$

$\mathrm{CV}_{\mathrm{W}}$ : Calorific Value of ignition wire $(1 \mathrm{~cm}=2.33 \mathrm{Kcal} / \mathrm{Kg})$

\section{Nitrogen Analysis}

0.5 gm of sample with 2.5 gm Kjeldahl mixture is taken in Kjeldahl flask. To this $12.5 \mathrm{ml}$ conc. $\mathrm{H}_{2} \mathrm{SO}_{4}$ is added, a dark red color forms, and the flask is kept in a digester, next part of the operation begins when the solution in the flask turns light green. In a beaker, $25 \mathrm{ml} 2 \%$ boric acid is added with 1-2 drops methyl red + methyl blue indicator and set aside. Now in a graduated cylinder the following is measured and carefully added to the Kjeldahl flask:

- $100 \mathrm{ml}$ distill water.

- $65 \mathrm{ml} 40 \% \mathrm{NaOH}$.

- $\quad$ Glass beads (3-4).

\section{- 1-2 drop phenolphthalein indicator.}

Now distillation process is started by connecting the flask with the condenser setup, where cooling fluid is liquid water. The outlet of the condenser is directed towards the beaker with boric acid in it, solution in it changes from dark red to light green as distillation progresses. Around $80 \mathrm{ml}$ of the solution is taken from the beaker, and then titrated with $0.1(\mathrm{~N}) \mathrm{H}_{2} \mathrm{SO}_{4}$. End point of titration is when the light green solution turns dark pink. Burette reading is noted.

$$
\begin{aligned}
& \text { Nitrogen } \%=\frac{(\text { Burettereading }- \text { blank }) \times 1.4 \times 100}{\text { Smapleweight } \times 1000} \\
& \text { Blank }=0.3 \mathrm{ml}
\end{aligned}
$$

\section{Chlorine Analysis}

Pellet made from pellet maker (0.7-0.9 gm) and 0.2 gm Benzoic acid is weighed into a quartz crucible. Absorbing solution; $10 \mathrm{ml}$ Chorine solution is added to the bomb. The bomb is pressurized with $99.5 \%$ Oxygen at $>30$ bar pressure. Bomb calorimeter process is followed, bomb is taken out after the process, after a short interval, the bomb is shaken for 3 minutes. Material inside is washed in $40 \mathrm{ml}$ distill water, filtered and clear solution is obtained. $10 \mathrm{ml}$ of this clear solution is taken, two drops potassium dichromate $\left(\mathrm{K}_{2} \mathrm{Cr}_{2} \mathrm{O}_{7}\right)$ as an indicator is added. Titration with $0.1(\mathrm{~N}) \mathrm{AgNO}_{3}$, end point is a yellowish red solution where precipitate can be clearly seen. Burette reading is noted.

Chlorine $\%=\frac{\text { Burette reading } \times \text { Normality of } \mathrm{AgNO}_{3} \times 35.44 \times 50}{10 \times \text { Weight of Biomass pellet } \times \text { FiltrateVolume }}$

Chlorine solution used is a mixture of $\mathrm{Na}_{2} \mathrm{CO}_{3}, \mathrm{NaHCO}_{3}$ and $\mathrm{H}_{2} \mathrm{O}_{2}$ solution at a specified combination.

\section{Sulfur Analysis}

Pellet is made from biomass sample using pellet maker $\left(\mathbf{X}_{1}\right)$, weighing in the range between 0.7-0.9 gm. Benzoic acid (around 0.2 $\mathrm{gm}$ ) is taken. Both the above are weighed into a quartz crucible. Bomb calorimeter process is followed for combustion, process remains same except $10 \mathrm{ml}$ distill water is taken in bomb using pipette, then after combustion the bomb is taken out, and a ten minute interval is taken, after that it is shaken for 3 minutes. $90 \mathrm{ml}$ distill water is poured in the bomb and crucible is also washed in it, inside the bomb. The above is filtered using Number 1 filter paper and clear solution is obtained. To $100 \mathrm{ml}$ clear solution, one drop methyl orange, and one gram barium chloride salt is added. The above is boiled at $250^{\circ} \mathrm{C}$ for one minute and covered with glass plate; kept overnight. Solution is then filtered with Filter paper 542 (ash-less). Filter paper is then washed with hot water repeatedly to remove chlorine, it can be checked using a solution of $\mathrm{AgNO}_{3}$; washing is done till white precipitate of $\mathrm{AgCl}$ no longer forms. Filter paper is dried in oven at around $50^{\circ} \mathrm{C}$ for one hour. Dried paper is now kept in a silica crucible, and put into muffle furnace for 2 hours at $550^{\circ} \mathrm{C}$. Ash formed is pure sulfur it is weighed for completion of calculation $\left(\mathbf{X}_{2}\right)$.

$$
\text { Sulfur } \%=\frac{\text { Weight of biomass pellet }\left(\mathrm{X}_{1}\right)}{\text { Weight of } A \operatorname{sh}\left(\mathrm{X}_{2}\right)} \times 13.73
$$

\section{Results and Discussion}

The materials taken for analysis are considered for quality combination to produce bio-pellets, which have good GCV and VM. Initially to understand how compressing a biomass material makes it energy rich is understood from Table 2 given below. Here raw material is wood chips and the finished pellets made from the same material are taken for analysis and compared to see the changes (Table 2). 
Citation: Bose D, Mekala A (2015) Analysis of Biomass in the Indian State of Gujarat for Sustainable Pellet Production. J Bioengineer \& Biomedical Sci 5: 166. doi:10.4172/2155- 9538.1000166

Page 3 of 4

Bulk density is an important parameter which indicates the ease of packing, the greater the value, more is the ease of packing, and we see a significant increase in the value from the feedstock to the end pellet. GCV for the raw material was relatively less but after pelletization the GCV is almost similar to Indian coal (Lignite) which has a GCV of around $4200 \mathrm{Kcal} / \mathrm{Kg}$.

It can be seen that moisture content has reduced and a significant increase in the volatile matter content is achieved, which signifies the combustible material present in the biomass. The ash content has also reduced in the final pellet.

Biomass is an energy lean fuel when it undergoes pelletization its mass density nd volume density increases and given that another comparison is made on the effect of pelletization on elemental analysis given below (Table 3).

Given that we have established the importance of pelletization, quality combination is now approached by mixing these biomass materials and then making them undergo pelletization. The binder used is starch diluted in certain percentage of water. A ring roll mill produces these pellets from the raw biomass (Table 4).

Average chlorine content in raw material for this combination $=4.14 \%$

Average sulfur content in raw material for this combination $=\mathbf{0 . 9 6 \%}$

Average nitrogen content in raw material for this combination $=\mathbf{2 . 2 5} \%$

From this analysis it is inferred that the pellet produced will have high VM content as in the raw material it is already $73.36 \%$, and there will be corresponding reduction in moisture and ash content as Table 2 has shown us (Table 5).

Average chlorine content in raw material for this combination $=4.33 \%$

\begin{tabular}{|l|l|}
\hline Raw Material Analysis & Pellet (Biofuel) Analysis \\
\hline Bulk Density $=\mathbf{2 5 3 . 4 6} \mathbf{~ K g} / \mathbf{m}^{\mathbf{3}}$ & Bulk Density $=\mathbf{5 7 8 . 0 1} \mathbf{~ K g} / \mathbf{m}^{\mathbf{3}}$ \\
$\mathrm{GCV}=\mathbf{3 4 6 9 . 6 3} \mathbf{~ K c a l} / \mathbf{K g}$ & GCV $=\mathbf{4 0 8 4 . 1 7} \mathbf{K c a l} / \mathbf{K g}$ \\
\hline Moisture $=8.95 \%$ & Moisture $=7.07 \%$ \\
Volatile matter $=68.88 \%$ & Volatile matter $=73.84 \%$ \\
Ash $=5.30 \%$ & Ash $=4.75 \%$ \\
Fixed Carbon $=16.87 \%$ & Fixed Carbon $=14.34 \%$ \\
\hline
\end{tabular}

Table 2: Raw material and Pellet comparison.

\begin{tabular}{|l|l|}
\hline Wood Chips (Raw Biomass) & Compressed pellets \\
\hline$\%$ Sulfur $=\mathbf{1 . 3 5 9} \%$ & $\%$ Sulfur $=\mathbf{0 . 0 2 6 5} \%$ \\
\hline$\%$ Chlorine $=5.64 \%$ & $\%$ Chlorine $=4.650 \%$ \\
\hline$\%$ Nitrogen $=2.75 \%$ & $\%$ Nitrogen $=3.158 \%$ \\
\hline
\end{tabular}

Table 3: Comparison in terms of sulfur, chlorine and nitrogen.
Average sulfur content in raw material for this combination $=\mathbf{0 . 9 1 \%}$

Average nitrogen content in raw material for this combination $\mathbf{1 . 8 6 \%}$

This combination is undesirable as it can be seen that sawdust has very low volatile matter content and hence has an effect on the overall quality of pellets that will be produced from it. Wood waste and wood strips being different kind of waste available maintains their quality (Table 6).

Average chlorine content in raw material for this combination $=\mathbf{5 . 4 4} \%$

Average sulfur content in raw material for this combination $=\mathbf{0 . 9 8} \%$

Average nitrogen content in raw material for this combination $\mathbf{1 . 9 8 \%}$

For this combination given in Table 6 wood waste is considered which in Gujarat is locally known as Jalau waste, since this is only available here. And this yields the best possible combination for the raw biomass material and in the raw material itself $0.98 \%$ sulfur is present hence in the pellet it will go further down which is important, as high percentage sulfur stremas contribute to corrosion of stacks in power plants (Table 7).

Average chlorine content in raw material for this combination $\mathbf{5 . 2 5} \%$

Average sulfur content in raw material for this combination $=\mathbf{0 . 4 5 \%}$

Averagenitrogen contentin rawmaterialforthiscombination $=\mathbf{2 . 6 6} \%$ When cotton stalk is considered as raw material which is an agricultural residue, the sulfur content is the lowest, but volatile matter content is less compared to the woody biomass material, and hence it brings down the VM percentage. A good fuel has volatile matter content in the range of $72-83 \%$, but since pelletization has the potential to increase this value, this combination is also accepted in the raw material for making pellets, which can be used for co-firing with coal in thermal power plants.

Hence the following observations are made from the analysis:

- Sawdust has the lowest Volatile matter.

- Wood strips have lowest moisture content.

- Prosopis has low ash content.

- Wood waste has low fixed carbon content.

\section{Conclusion}

Biomass can be compressed to form pellets using suitable binders and then use them in co-firing with coal in steam turbine based power

\begin{tabular}{|c|c|c|c|c|c|c|}
\hline Raw Material & Bulk Density $\left(\mathrm{Kg} / \mathrm{m}^{3}\right)$ & $\begin{array}{l}\text { Moisture } \\
\text { (\%) }\end{array}$ & Volatile Matter (\%) & Ash (\%) & Fixed Carbon (\%) & \\
\hline Prosopis & 185.55 & 14.04 & 76.20 & 4.01 & 5.75 & \multirow{4}{*}{$\begin{array}{l}100 \% \\
100 \% \\
100 \% \\
100 \%\end{array}$} \\
\hline Cotton Stalk & 241.46 & 10.42 & 65.11 & 7.02 & 17.44 & \\
\hline Wood Strips & 161.06 & 10.67 & 78.78 & 10.67 & 4.06 & \\
\hline Total & $\begin{array}{l}\text { Average Bulk Density } \\
196.02 \mathrm{Kg} / \mathrm{m}^{3}\end{array}$ & $\begin{array}{l}\text { Avg. MS } \\
11.71 \%\end{array}$ & $\begin{array}{l}\text { Avg. VM } \\
73.36 \%\end{array}$ & $\begin{array}{l}\text { Avg. Ash } \\
7.23 \%\end{array}$ & $\begin{array}{l}\text { Avg. Fixed Carbon } \\
9.08 \%\end{array}$ & \\
\hline
\end{tabular}

Table 4: Quality combination I using three different biomass materials. 
Citation: Bose D, Mekala A (2015) Analysis of Biomass in the Indian State of Gujarat for Sustainable Pellet Production. J Bioengineer \& Biomedical Sci 5: 166. doi:10.4172/2155- 9538.1000166

Page 4 of 4

\begin{tabular}{|c|c|c|c|c|c|c|}
\hline Raw Material & Bulk Density $\left(\mathrm{Kg} / \mathrm{m}^{3}\right)$ & Moisture (\%) & Volatile Matter (\%) & Ash (\%) & Fixed Carbon (\%) & \\
\hline Wood Waste & 176.16 & 11.34 & 70.69 & 9.38 & 5.24 & \multirow{4}{*}{$\begin{array}{l}100 \% \\
100 \% \\
100 \% \\
100 \%\end{array}$} \\
\hline Sawdust & 152.89 & 12.95 & 58.23 & 6.98 & 21.84 & \\
\hline Wood Strips & 161.06 & 10.67 & 78.78 & 10.67 & 4.06 & \\
\hline Total & $\begin{array}{l}\text { Average BD } \\
163.37 \mathrm{Kg} / \mathrm{m}^{3}\end{array}$ & $\begin{array}{l}\text { Avg. MS } \\
11.65 \%\end{array}$ & $\begin{array}{l}\text { Avg. VM } \\
69.23 \%\end{array}$ & $\begin{array}{l}\text { Avg. Ash } \\
9.01 \%\end{array}$ & $\begin{array}{l}\text { Avg. Fixed Carbon } \\
10.38 \%\end{array}$ & \\
\hline
\end{tabular}

Table 5: Quality combination II using three different biomass materials.

\begin{tabular}{|c|c|c|c|c|c|c|}
\hline Raw Material & Bulk Density $\left(\mathrm{Kg} / \mathrm{m}^{3}\right)$ & Moisture(\%) & Volatile Matter (\%) & Ash (\%) & Fixed Carbon (\%) & \\
\hline Prosopis & 185.55 & 14.04 & 76.20 & 4.01 & 5.75 & \multirow{4}{*}{$\begin{array}{l}100 \% \\
100 \% \\
100 \% \\
100 \%\end{array}$} \\
\hline Wood Waste & 176.16 & 11.34 & 70.69 & 9.38 & 5.24 & \\
\hline Wood Strips & 161.06 & 10.67 & 78.78 & 10.67 & 4.06 & \\
\hline Total & $\begin{array}{l}\text { Average Bulk Density } \\
174.25 \mathrm{Kg} / \mathrm{m}^{3}\end{array}$ & $\begin{array}{l}\text { Avg. MS } \\
12.01 \%\end{array}$ & $\begin{array}{l}\text { Avg. VM } \\
75.22 \%\end{array}$ & $\begin{array}{l}\text { Avg. Ash } \\
8.02 \%\end{array}$ & $\begin{array}{l}\text { Avg. Fixed Carbon } \\
5.01 \%\end{array}$ & \\
\hline
\end{tabular}

Table 6: Quality combination III for the raw biomass material.

\begin{tabular}{|c|c|c|c|c|c|c|}
\hline Raw Material & Bulk Density $\left(\mathrm{Kg} / \mathrm{m}^{3}\right)$ & Moisture (\%) & Volatile Matter (\%) & Ash (\%) & Fixed Carbon (\%) & \\
\hline Cotton Stalk & 241.46 & 10.42 & 65.11 & 7.02 & 17.44 & \multirow{4}{*}{$\begin{array}{l}100 \% \\
100 \% \\
100 \% \\
100 \%\end{array}$} \\
\hline Wood Waste & 176.16 & 11.34 & 70.69 & 9.38 & 5.24 & \\
\hline Wood Chips & 176.16 & 11.34 & 70.28 & 5.05 & 13.33 & \\
\hline Total & $\begin{array}{l}\text { Average Bulk Density } \\
197.92 \mathrm{Kg} / \mathrm{m}^{3}\end{array}$ & $\begin{array}{l}\text { Avg. MS } \\
11.03 \%\end{array}$ & $\begin{array}{l}\text { Avg. VM } \\
68.69 \%\end{array}$ & $\begin{array}{l}\text { Avg. Ash } \\
7.13 \%\end{array}$ & $\begin{array}{l}\text { Avg. Fixed Carbon } \\
12.01 \%\end{array}$ & \\
\hline
\end{tabular}

plants and these pellets will have other heating application as well, hence lower flue gas emission altogether. The global population stand around seven billion people and predicted to rise to more than nine billion by 2050 , as reliance on fossil fuels will start to drop, increase in the share of renewables should increase, to contribute to energy security of each nation. Renewable energy, though intermittent in nature is humanity's best chance to combat global warming, climate change and rising energy demands [5]. Present energy scenario demands a comprehensive rethink of the existing model of production and consumption, where one's output is another's input, and obsession with ownership of material goods is moderated. Doing this would help us have healthier food, more efficiently managed resources, a cleaner environment, and a safer, more resilient and equitable world.

\section{References}

1. Beck F, Martinot E (2004) Renewable Energy Policies \& Barriers. Encyclopedia of energy $5: 365-383$.

2. State-wise potential of various renewable energy technologies.

3. http://pmindia.gov.in/report_to_people/2012-2013/report_PMO_English.pdf

4. Meisen P, Quéneudec E (2006) Overview of sustainable renewable energy potential of India. Global Energy Network Institute 1-26.

5. World Population to EXCEED 9 billion by 2050: Developing Countries to Add 2.3 Billion Inhabitants with 1.1 Billion Aged Over 60 and 1.2 Billion of Working Age (2009) Press Release. 